WwW.jmscr.igmpublication.org

Impact Factor (SJIF): 6.379

Index Copernicus Value: 79.54

ISSN (e)-2347-176x ISSN (p) 2455-0450

crossrefDOI: https://dx.doi.org/10.18535/jmscr/v6i10.79

\title{
Use of Rubber Band Ligation and Micronized Flavanoid in the Treatment of Hemorrhoid: A Comparative Study
}

Authors

\author{
Dr AKM Shamsuddin ${ }^{1}$, Dr Nasrin Sultana ${ }^{2}$, Dipok Chandra Kirtonia ${ }^{3}$, \\ Dr Major Mohammad Alom ${ }^{4}$, Lt Col Dr Md Nazmul Hoque ${ }^{5}$ \\ ${ }^{1}$ Asst.Professor, Paediatric Surgery, Patuakhali Medical College \& Hospital, Potuakhali \\ ${ }^{2}$ Junior Consultant, Gynae \& Obs, Mohammadpur Fertility Centre, Dhaka \\ ${ }^{3}$ Asst. Professor, Dept. of Surgery, Patuakhali Medical College \& Hospital, Patuakhali \\ ${ }^{4}$ Surgical Specialist, Border Guard Hospital, Peelkhana, Dhaka \\ ${ }^{5}$ CEO, Border Guard Hospital, Peelkhana, Dhaka
}

\begin{abstract}
Background: Hemorrhoid is a common cause of per rectal bleeding of all sexes. There are many options for the management of hemorrhoid depending on symptoms and degree of hemorrhoids. Rubber band ligation and micronised flavanoids (Oral Agent) have used in early symptomatic hemorrhoid.

Aims: To find out the effectiveness of rubber band ligation (RBL) and micronized flavanoid in the treatment of hemorrhoid.

Patients and Methods: Uncomplicated 120 patients with $1^{\text {st }}$ and $2^{\text {nd }}$ degree hemorrhoid were selected by proctoscopy. RBL and 'Oral Agent' were applied to 60 patients each. Recovery from bleeding, time needed to relief symptoms and presence of complication were observed to measure outcome.

Results: Complete cure from bleeding seen with $91 \%$ cases of rubber band ligation and $82 \%$ cases after 'Oral Agent' use. Early cure seen after RBL and that was $3^{\text {rd }}$ day after use. After RBL and 'Oral Agent' application $95 \%$ and $85 \%$ showed their satisfaction regarding treatment.
\end{abstract}

Keywards: Hemorrhoid, Rubber Band Ligation, Micronised Flavanoid.

\section{Introduction}

Rupture of dilated haemorrhoidal vessels causes painless per rectal bleeding and usually common in both male and female ${ }^{1}$.Haemorrhoid presents as external or internal in relation to the dentate line. Primary hemorrhoid located in three position as 3,7 and 110 'clock position. According to the extension of disease haemorrhoid is classified as $1^{\text {st }}$ degree: Bleeding piles without prolapsed. $2^{\text {nd }}$ degree: Bleeding with prolapsed and reduce spontaneously. $3^{\text {rd }}$ degree: Bleeding hemorrhoid with prolapsed that need digital reduction and $4^{\text {th }}$ degree: Prolapsed hemorrhoids unable to reduce ${ }^{2}$. $1^{\text {st }}$ and $2^{\text {nd }}$ degree considered as early stage and $3^{\text {rd }}$ and $4^{\text {th }}$ degree considered as advance disease. Advanced stages of heamorrhoids needs surgical intervention $^{3}$ but for early stage disease there are multiple treatment options with variable success rates. This includes rubber band ligation (RBL), sclerosant injection, cryosurgery, electro 
coagulation and $90 \%$ diosmin and $10 \%$ hesperidin (Oral Agent) ${ }^{4}$.

RBL is safe, effective, convenient and easy to apply acts mechanically strangulating pedicle of hemorrhoids ${ }^{4}$. (Oral Agent) causes prolong contraction of heamorrhoidal veins increase local lymphatic drainage and decrease synthesis of PGE2 and Thromboxane A2 responsible for local inflammation ${ }^{5}$. Both procedure have minimum side effects like mild GIT and local inflammation. Both options are widely practiced with variable success. That's why this study was done to find out effective treatment of early symptomatic hemorrhoid.

\section{Material and Methods}

This prospective study was carried out on 120 OPD patients of Border Guard Hospital Peelkhana, Dhaka, after adequate counseling of treatment. Patients were selected by proctoscopy examination seeking treatment for per rectal bleeding. Complicated piles, $3^{\text {rd }}$ and $4^{\text {th }}$ degree piles and treated surgically earlier for hemorrhoids were excluded from the study. RBL was applied on 60 OPD patients with the help of RBL application set up. Whereas the 'Oral Agent' was given to another 60 patients with a schedule of 3 tab. twice daily for 4 days then 2 tab twice daily for 3 days and finally 1 tab twice daily for 2 months. All patients were followed up on $3^{\text {rd }}$ and $7^{\text {th }}$ day and $2^{\text {nd }}$ week, $6^{\text {th }}$ week and on $12^{\text {th }}$ week after treatment. State of per rectal bleeding, appearance of any new local or general symptoms and patient's satisfaction were observed. During each follow up treatment outcome were measured as a group. Group a: complete cure on history and examination. Group b: minimum symptoms remaining. Group c: no improvement at all. Group d: new symptoms appeared.

\section{Results}

In this study mean age of the patients were $38 \pm 2.4$ years and $40 \pm 1.9$ years in RBL and 'Oral Agent' group and male female ratio was $2.5: 1$ and $1.4: 1$ respectively. Average duration per rectal bleeding before treatment was $5.6 \pm 2.5$ days and $6.3 \pm 1.7$ days. Pain, constipation and Pruritus Ano were commonly associated symptoms of both groups. On proctoscopy $43.33 \%$ (26) and 56.66\% (34) had $1^{\text {st }}$ and $2^{\text {nd }}$ degree haemorrhoids of BRL group. In 'Oral Agent' group 35\% (21) and 65\% (39) patients had $1^{\text {st }}$ and $2^{\text {nd }}$ degree hemorrhoids.

It was observed that after application RBL complete arrest of bleeding within 7 days fond in $80 \%$ patients and in After 'Oral Agent' application it was $76.66 \%$. After 12 weeks of treatment, complete cessation of bleeding found $86.66 \%$ and $88.33 \%$ in RBL group and 'Oral Agent' group respectively. Non response seen 9.16\% (11) and 7.5\% (9) cases of RBL and 'Oral Agent' group. Two patients of both group needed surgical intervention within 12 weeks due to worsening symptoms.

Table1: General parameters of both groups included for treatment

\begin{tabular}{|l|c|c|c|}
\hline Parameter & & $\begin{array}{c}\text { Rubber Band } \\
\text { Ligation }\end{array}$ & Oral Agent \\
\hline Age & & $38 \pm 2.4$ yrs & $40 \pm 1.9$ yrs \\
\hline Sex & Male & $43(71.66) \%$ & $35(58.33) \%$ \\
\hline & Female & $17(28.33) \%$ & $25(41.66) \%$ \\
\hline Bleeding & Mild (Few ml) & $38(63.33) \%$ & $41(68.33) \%$ \\
\hline & $\begin{array}{c}\text { Moderate } \\
(<100 \mathrm{ml} / \text { day })\end{array}$ & $18(30) \%$ & $22(36.66) \%$ \\
\hline & $\begin{array}{c}\text { Severe } \\
(>100 \mathrm{ml} / \text { day })\end{array}$ & $4(6.66) \%$ & $7(11.47) \%$ \\
\hline $\begin{array}{l}\text { Associated } \\
\text { symptoms }\end{array}$ & Peri anal pain & & \\
\hline & Constipation & & \\
\hline & Prolapsed & & \\
\hline & Pruritus ani & & $39(65) \%$ \\
\hline & & & \\
\hline Proctoscopy & $1^{\text {st }}$ degree & $26(43.33) \%$ & $21(35 \%)$ \\
\hline & $2^{\text {nd }}$ degree & $3456.66) \%$ & $39(2)$ \\
\hline
\end{tabular}

Table 2: Arrest of bleeding after treatment

\begin{tabular}{|l|c|c|}
\hline $\begin{array}{l}\text { Arrest of } \\
\text { bleeding }\end{array}$ & Rubber band ligation & Oral Agent \\
\hline $1^{\text {st }}$ week & $48(80) \%$ & $46(76.66) \%$ \\
\hline $4^{\text {th }}$ week & $50(83.33) \%$ & $52(8 / 6.66) \%$ \\
\hline $6^{\text {th }}$ week & $50(83.33) \%$ & $53(88.33) \%$ \\
\hline $12^{\text {th }}$ week & $52(86.66) \%$ & $53(88.33) \%$ \\
\hline
\end{tabular}


Table 3: Response pattern of treatment of both groups

\begin{tabular}{|c|c|c|}
\hline Response type & RBL & Oral Agent \\
\hline a & $52(86.66) \%$ & $53(88.33) \%$ \\
\hline b & $4(6) \%$ & $5(8.33) \%$ \\
\hline c & $4(6) \%$ & $3(5) \%$ \\
\hline d & $1(1) \%$ & 0 \\
\hline e & $4(6) \%$ & $5(8.33) \%$ \\
\hline
\end{tabular}

a: complete cure of bleeding

b: remaining minimum symptoms

c: no response

$\mathrm{d}$ : Condition worsening after treatment

e: relapse after treatment

\section{Discussion}

Bleeding through anus is commonly associated with haemorrhoids both in male and female ${ }^{6}$. Primary haemorroids were commonly found in 3, 7and 110 'clock position around anus. Surgical treatment is reserved for both $3^{\text {rd }}$ and $4^{\text {th }}$ degree $^{6}$. In this study haemorrhoids were present at the end of $3^{\text {rd }}$ decade of life and male female ratio was 1.4:1. Patients were presented with mean duration of bleeding were $5.6 \pm 2.5$ days in RBL and $6.3 \pm 1.7$ days in 'Oral Agent' group. In $1^{\text {st }}$ visit at the end of $7^{\text {th }}$ day $80 \%$ and $76.66 \%$ patients experienced complete arrest of bleeding in RBL and 'Oral Agent' treatment respectively. At the end of 12 weeks $86.66 \%$ and $88.33 \%$ of RBL and 'Oral Agent' treatment experienced complete cessation of bleeding. Achievement of success is similar in both group and statistically significant but difference between groups is not significant. Few patients needed surgical intervention as condition worsening after treatment that is $9.16 \%$ of RBL and 7.5\% of 'Oral Agent' category needed surgical treatment. Disease reappear after 12 weeks of $6 \%$ of RBL and 8\% (Oral Agent) treatment.

\section{Conclusion}

Rubber band ligation had rapid action on $1^{\text {st }}$ and $2^{\text {nd }}$ degree haemorrhoids to arrest bleeding. Micronized flavanoid had similar action on arrest haemorrhoidal bleeding but takes a bit longer time to act upon. Both methods had similar success in controlling haemorrhoidal bleeding. Micronized flavanoid is less convenient as it is costly and needs prolong intake of medicine.

\section{References}

1. Brisinda G, How to treat haemorrhoids. BMJ 2000;321:582-3.

2. Miligan ETC, Morgan CN, Jones LE, Officers R. Surgical anatomy of anal and operative treatment of Haemorrhoids. Lancet 1937;ii:1119-24.

3. Bayer I, Mislovety C, Pikovolky BM. Rubber band ligation of haemorrhoids. Convenient economic treatment. J Clin Gastroenterol 1996;23:50-2.

4. Labrid C, Dahault J Vix C. Pharmacological properties of Daflon 500mg. Int Jr Med. 1987;85: 30-5.

5. Misra MC and Prashad R. Randomised clinical trial of Micronised flavanoids in the early bleeding from acute internal haemorrhoids. Br Jr surgery 2000;868-72.

6. Pushpinder S, Sandhu, Shing K. A randomized comparative study of Micronised flavanoids and rubber band ligation in the treatment of acute internal haemorrhoids. Ind J Surg 2004;66:5:281-5.

7. Cospite $\mathrm{M}$ and Cospite V. Treatment of haemorrhoids with Daflon $500 \mathrm{mg}$. Phlebology 1992;7:53-6.

8. Ho YH, Margaret AN, Choin FS. Micronised purified Flavonoid Fraction compared with rubber band ligation and fiber alone in the management of bleeding haemorrhoids. Dis Colon Rectum 2000;43:66-9.

9. Morris PJ and Malt RA. Oxford Textbook of Surgery. 1994;1:1127. 